\title{
A Review of the Monograph by D. L. Motov and M. M. Godneva "Fluoric, Sulfatic, and Fluorosulfatic Compounds of Group IV Elements: Forming \& Properties"
}

DOI: $10.1134 / \mathrm{S} 003602361005027 \mathrm{X}$

The monograph deals with the formation and principal characteristics of fluorides, sulfates and fluorosulfates of the group IV elements. Presenting the results of numerous experimental studies of the authors published and translated in English earlier it also provides analysis of the currently available literature.

The 21 physical-chemical systems and 8 sections examined by the authors are described from the viewpoint of formation of their compounds in aqueous media, with demarcating the formation regions, determining the chemical composition and key characteristics such as refractometric, roentgenometric, IR-spectroscopic, and thermal ones and including heat treatment data.

Systematic studying the systems has resulted in discovery of more than one hundred of new compounds and determining their structural parameters and types of chemical bonds which, when compared with known data, has allowed the identification of a new class of compounds, namely, fluorosulfatemetallates.

By comparing the systematized compounds, represented by 37 series and 9 groups and including 400 items, there has been predicted the possibility of formation of about 30 new compounds of titanium, zirconium and hafnium with various outher-sphere cations.

Apart from its chemical content, the book may serve as an atlas of infrared absorption spectra, derivatograms, roentgenometric, refractometric, and crystallographic data on the compounds discussed.

The monograph be of interest for researchers involved in studies of transition elements chemistry, for process engineers concerned with fluorine chemistry, as well as for college professors and students of relevant specialities.

N. N. Grishin, Dr. Sc. (Chemistry) 